2. Patel T, Wong J. The role of real-time interactive video consultations in dental practice during the recovery and restoration phase of the COVID-19 outbreak. Br Dent J 2020; 229: 196-200.

3. Gladwin L. From face-to-face to face-time: is the future of dental appointments virtual? Br Dent J 2020; 229: 301.

4. Greenhalgh T, Vijayaraghavan S, Wherton J et al. Virtual online consultations: advantages and limitations (VOCAL) study. BMJ Open 2016; 6: e009388. doi:10.1136/bmjopen-2015-009388.

https://doi.org/10.1038/s41415-020-2236-9

\section{Bio-fuel from PPE}

Sir, I concur with your correspondent R. Dean $^{1}$ on the unprecedented usage of PPE (personal protective equipment) leading to the other PPE (polluting Planet Earth). One good alternative to protect Mother Nature in this situation is the conversion of plastic waste material into a liquid biofuel. Pyrolysis is the procedure of conversion of any material at very high temperatures. All PPEs which at present are disposed in landfills, oceans, etc, which impose negatively on aquatic animals, can be transferred to an incinerator and then pyrolysis can be done to break down the propylene chains to form a liquid. The liquid obtained can be used as a biofuel. We are very much in need of fuel for the operation of various mechanical devices.
This biofuel can be further reused thus protecting our planet. Due to the increasing population and their demand for energy consumption, this would serve as a healthy alternative and also preserve our nature. ${ }^{2}$

N. Elisetti, Telangana, India

\section{References}

1. Dean R. PPE: polluting Planet Earth. Br Dent J 2020; 229: 267.

2. Jain S, Lamba B Y, Kumar S, Singh D. Strategy for repurposing of disposed PPE kits by production of biofuel: Pressing priority amidst COVID-19 pandemic. Biofuels 2020. https://doi.org/10.1080/17597269.202 0.1797350

https://doi.org/10.1038/s41415-020-2237-8

\section{Pharmaceuticals}

\section{Dexamethasone caution}

Sir, were Dexamethasone to be included in the Dental Formulary, practitioners need to be aware of common and important physical and psychiatric side effects of this potent glucocorticoid (steroid), prior to prescribing for the control of pain related to root canal treatment.

It is widely recognised that steroids can cause or worsen hyperglycaemia, and national guidelines recommend monitoring glucose levels in those with and at risk of diabetes. ${ }^{1}$ Although much of the evidence concerns long term steroid use, hyperglycaemia has been frequently reported after short courses, for example in oncology practice. $^{2}$

Glucose levels can rise within hours of high dose steroids, with a disproportionate effect on afternoon and evening levels. ${ }^{3,4}$ Patients with or at risk of diabetes therefore need to be counselled to monitor their glucose levels after taking dexamethasone and may need to make short term adjustments of their diabetes therapy.

Even short courses of Dexamethasone in the peri-operative period may have an impact on wound healing, ${ }^{5}$ which would be relevant to the proposed use in endodontics.

Another established side effect of Dexamethasone is that it can cause steroid induced psychiatric reactions, including psychosis, mood changes, behavioural disturbance and cognitive dysfunction. These symptoms can develop within days of a $5 \mathrm{mg}$ single dose even in those who have no psychiatric history. ${ }^{6,7,9}$ The incidence of a psychiatric episode to steroids has been recorded at being between $13 \%$ and $62 \%{ }^{8}$ Many of these are mild reactions such as euphoria and increased irritability and may not impact on functioning, but patients need to be warned about the severe reactions in up to $5-6 \%$ of patients, ${ }^{8,10}$ such as mania and suicidal thoughts. Severe and persistent symptoms will require treatment which is beyond the remit of the dentist.

Whilst Dexamethasone may reduce pain related to endodontic procedures ${ }^{11,12}$ it is not a drug to be used when other safer treatment options may be available. We would be opposed to it being more widely available.

S. I. Morganstein, D. L. Morganstein, L. R. Morganstein, London, UK

\section{References}

1. JBDS-IP. Joint British Diabetes Societies for inpatient care. Management of hyperglycaemia and steroid (glucocorticoid) therapy. October 2014. Available at: https://www.diabetes.org.uk/resources-s3/2017-09/ JBDS\%20management\%20of\%20hyperglycaemia\%20 and\%20steriod\%20therapy_0.pdf (accessed 18 March 2018).

2. Véber O, Wilde A, Demeter J Tamás G, Mucsi I, Tabák A $G$. The effect of steroid pulse therapy on carbohydrate metabolism in multiple myeloma patients: a randomized crossover observational clinical study. $\rfloor$ Endocrinol Invest 2014; 37: 345-351.

3. Burt M G, Roberts G W, Aguilar-Loza N R, Stranks S N. Continuous monitoring of circadian glycemic patterns in patients receiving prednisolone for COPD. J Clin Endocrinol Metab 2011; 96: 1789-1796.

4. Lyall M J, Thethy I, Steven L et al. Diurnal profile of interstitial glucose following dexamethasone prophylaxis for chemotherapy treatment of gynaecological cancer. Diabet Med 2018; 35: 1508-1514.

5. Polderman J A, Farhang-Razi V, Van Dieren S et al. Adverse side effects of dexamethasone in surgical patients. Cochrane Database Syst Rev 2018; 11: CD011940.

6. Janes M, Kuster S, Goldson T M, Forjuoh S N. Steroidinduced psychosis. Proc (Bayl Univ Med Cent) 2019; 32: 614-615.

7. American Psychiatric Association aww. Diagnostic and statistical manual of mental disorders: DSM-5. 5th edition. Washington, DC: American Psychiatric Association, 2013.
8. Lewis D A, Smith R E. Steroid-induced psychiatric syndromes: A report of 14 cases and a review of the literature. J Affect Disord 1983; 5: 319-332.

9. Silva R G, Tolstunov L. Steroid-induced psychosis: report of case. J Oral Maxillofac Surg 1995; 53: 183-186.

10. Corticosteroids: easy psychiatric side-effects. September 2007. Available at: https://www.gov.uk/ drug-safety-update/corticosteroids-early-psychiatricside-effects (accessed 26 July 2020).

11. Nogueira B L, Silva L, Mesquita C M et al. Is the use of dexamethasone effective in controlling pain associated with symptomatic irreversible pulpitis? A systematic review. J Endod 2018; 44: 703-710.

12. Konagala R K, Mandava J, Pabbati R K et al. Effect of pretreatment medication on postendodontic pain: a double-blind, placebo-controlled study. J Conserv Dent 2019; 22: 54-58.

https://doi.org/10.1038/s41415-020-2238-7

\section{Co-codamol okay}

Sir, I was surprised to read an article $(B D J$ 2020; 229: 15-18) reporting that dentists cannot prescribe co-codamol. I have been prescribing it for years on a private prescription in different practices and never had an issue with it, as well as other drugs that are not on the dental practitioners section of the BNF.

After seeing the article, I checked the GDC website where it states: 'A dentist can prescribe any medicine from the British National Formulary (BNF) on a private prescription; however you must only prescribe medicines to meet the identified dental needs of your patients'. As for myself, I believe that many colleagues that deal with surgical procedures are prescribing it as it would be very counterproductive and difficult to seek medical advice every time you have procedures that are bound to cause moderate to severe pain. In that same light I believe that we may prescribe any medications that we judge to be beneficial and justifiable for the patient's dental condition.

D. Silveira, London, UK

https://doi.org/10.1038/s41415-020-2239-6 